\title{
Cuevas volcánicas: entre la realidad y la ficción
}

\author{
Rafael Antonio López Martínez, Raquel Daza y Rocio Alcántara
}

\begin{abstract}
Resumen
El estudio de las cuevas volcánicas ha despertado el interés de los científicos de todo el mundo, debido a sus microorganismos únicos y a la posibilidad de su uso como análogos marcianos. Sin embargo, en México existen pocos estudios al respecto, pero una enorme cantidad de cuevas volcánicas por explorar y estudiar. El presente trabajo narra el proceso de investigación y los resultados obtenidos por un grupo de investigadores del Instituto de Geología de la Universidad Nacional Autónoma de México (UnAM) en el estudio del tubo de lava de Chimalacatepec, en México.
\end{abstract}

Palabras clave: tubos de lava, estromatolitos, cuevas.

\section{VOLCANIC CAVES BETWEEN THE REALITY AND FICTION}

\begin{abstract}
The study of volcanic caves is a topic of interest for scientists worldwide. This is due to the unique microorganisms they contain and its possible use as Martian analogs. Despite the high number of lava caves in Mexico, there are only few scientific studies. This article narrates the process and results of the investigations in Chimalacatepec lava caves conducted by researchers from the Institute of Geology of the National Autonomous University of Mexico (UNAM).
\end{abstract}

Keywords: lava tubes, stromatolites, caves.

Recepción: 13/06/2020. Aprobación: 27/01/2021. Dol: http://doi.org/10.22201/cuaieed.16076079e.2021.22.2.3 


\section{Rafael Antonio López Martínez}

ralopezm@geologia.unam.mx orcid.org/0000-0002-5357-5583

Researchgate: Rafael_Lopez-Martinez Geología.unam.mx: Rafael-Antonio-Lopez

Doctor en Ciencias de la Tierra e Investigador Tiempo Completo del Instituto de Geología de la unam. Dirige el laboratorio de Carbonatos y Procesos Kársticos de dicho Instituto. Desarrolla la línea de investigación del karst y pseudokarst que incluye cuevas en diferentes ambientes como las volcánicas. Ha publicado diversos artículos científicos sobre el tema y dirigido diversas tesis de nivel licenciatura, Maestría y Doctorado sobre cuevas en México.

\section{Raquel Daza}

raqueldb@geologia.unam.mx orcid.org/0000-0001-7049-2627

Licenciada en Geología e Ingeniería geológica (universidad Autónoma de Barcelona). Maestría en Exploración de reservorios sedimentarios (Universidad de Barcelona). Doctora en geología (Universidad Complutense de Madrid). Especialista en estudios del karst y pseudokarst: distribución, composición y génesis (biótica/abioótica) de los espeleotemas de cuevas volcánicas (Azores, galápagos, estados unidos y México). Investigadora y docente en el Instituto de Geología, Facultad de ciencias Universidad Autónoma de México y en el Instituto Universitario de Yucatán.

\section{Rocio Jetzabel Alcántara Hernández}

ralcantarah@geologia.unam.mx orcid.org/0000-0002-6626-715X

Geología.unam.mx: Alcantara-Hernandez-Rocio-Jetzabel

Investigadora en el área de Geomicrobiología en el Instituto de Geología de la UNAM. Especialista en bacterias y arqueas y sus funciones. Dirige un grupo de investigación que explora la diversidad de los microorganismos en suelo, lagos, acuíferos, cuevas, sedimentos y tapetes microbianos, así como en biorreactores para el tratamiento de residuos. Estudió Química en la Universidad Autónoma del Estado de México, y cuenta con un Doctorado en Biotecnología y Bioingeniería por el Centro de Investigación y de Estudios Avanzados del Instituto Politécnico Nacional (cinvestAv). Ha publicado artículos en revistas internacionales indexadas, capítulos de libro y un libro; y ha impartido clases durante los últimos 7 años en el área de Microbiología y Biorremediación a nivel licenciatura y posgrado. Asimismo, ha dirigido proyectos de tesis de alumnos de licenciatura, maestría y actualmente doctorado. 


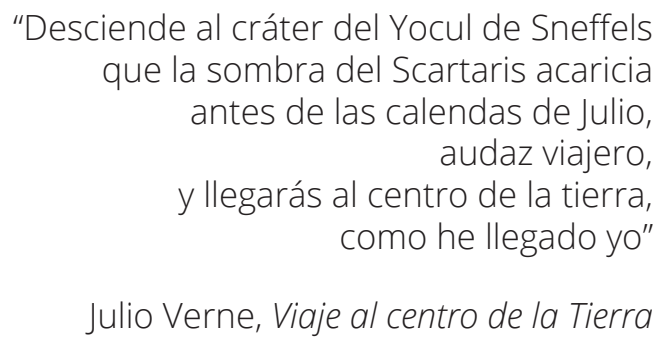

\section{Viaje al centro de la tierra}

Habían pasado muchos años desde que el libro de Julio Verne (1828-1905) había estado en la cabecera de mi cama, pero la conversación entre el profesor Lidenbrock y Axel se repetía una y otra vez en mi cabeza. ¿Será acaso que las palabras de Arne Saknussemm sobre cómo penetrar a las entrañas de la tierra a través de un volcán de Islandia puedan guiarme en México? ¿Encontraremos también formaciones y criaturas maravillosas? Tal vez, sólo tal vez, me había convertido en verniano sin darme cuenta y en ese momento me encontraba conduciendo desde el Instituto de Geología de la unam hacia Tepoztlán en busca de mi propio Sneffels.

Recordaba perfectamente cómo el profesor describía la montaña de 5000 pies de altura (1524 metros sobre el nivel del mar) y no pude evitar sonreír, trasladarme a aquella sala y decirle:

—Profesor, voy rumbo al poblado de San Juan Tlacotenco, a más de 2400 metros de altura, con numerosos cuerpos volcánicos extintos y kilómetros de cuevas volcánicas mapeadas.

Evidentemente, nunca le hablé a mis compañeros de viaje sobre esta plática o me tildarían de loco o, al menos, de verniano. 


\section{Snæfellsjökull mexicano}

Las cuevas volcánicas, también llamadas tubos de lava, se forman en complejos volcánicos activos, en los que la parte exterior del flujo se enfría y solidifica mientras que en el interior sigue fluyendo lava a través de conductos subterráneos (Detay y Hróarsson, ver figura 1).

Figura 1. Formación de los tubos de lava. A. El flujo de lava desciende por la ladera del volcán. La lava fundida tiende a canalizarse y, en contacto con el aire y la roca adyacente, se enfría muy rápido. Así, se forma una corteza más o menos endurecida por enfriamiento de la superficie de la colada y un aislamiento del flujo de lava líquida interior. B. La erupción volcánica cesa y se reducen las emisiones de lava. El nivel del flujo lávico interior decrece por lo que se forma un espacio vacio bajo la corteza. La lava sigue circulando por el tubo lávico. C. Cese total de la erupción y formación del tubo de lava o cueva volcánica. Aparecen colapsos parciales de techo a lo largo del tubo, debidos a la última fase de enfriamiento, estos agujeros se denominan ventanas o skylights en inglés. En fases posteriores ocurre la colonización de las entradas y alrededores por la vegetación. Diagrama elaborado por Raquel Daza.

Figura 2. Mapa de la cueva Chimalacatepec comparada con la Torre Latinoamericana. La topografía original de la cueva fue realizada por el Dr. Ramón Espinaza Pereña.

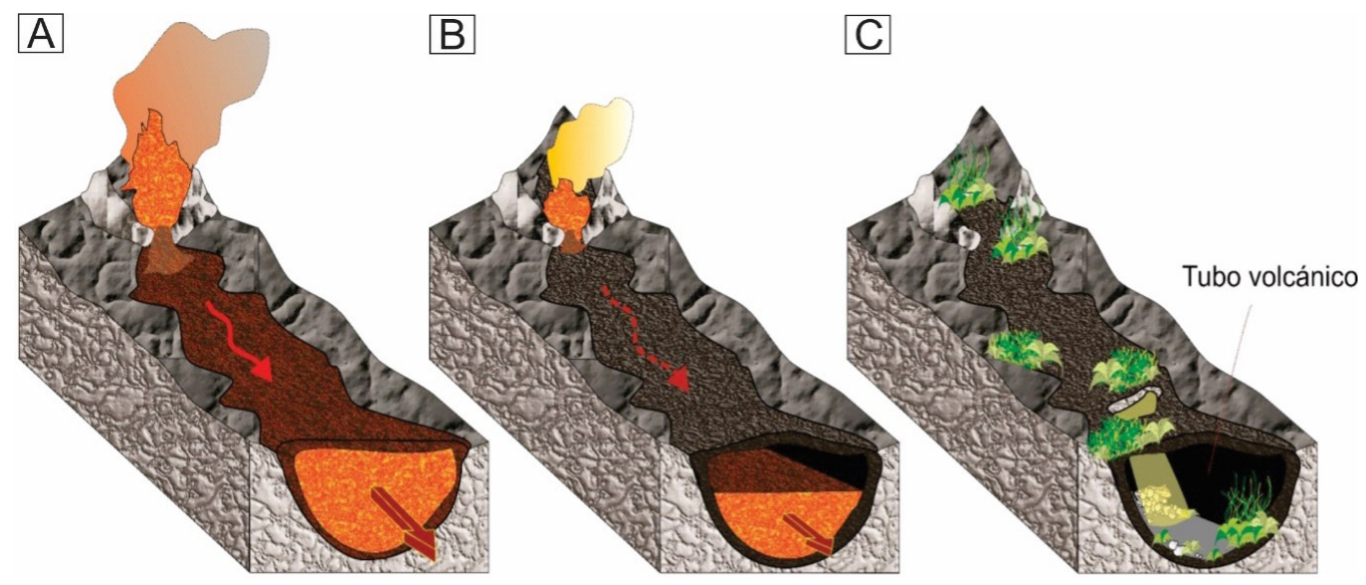

Fue a través de estos conductos que Julio Verne imaginó un viaje hasta el centro de la Tierra, lleno de aventuras y criaturas extraordinarias. En México, existe un área llamada el Cinturón Volcánico Transmexicano que posee una gran variedad de tubos de lava y maravillas dignas de una novela de Verne.

Dentro de esta área hay una cueva muy especial llamada cueva de Chimalacatepec, mapeada por el Dr. Ramón Espinasa Pereña hace algunos ayeres. Esta cueva se encuentra en el interior de uno de los derrames de lava del volcán Suchiooc, en el estado de Morelos y tiene un poco más de 200 m de profundidad. Es decir, sería un poco más profunda que bajar la Torre Latinoamericana; claro está, desde la antena (ver figura 2).
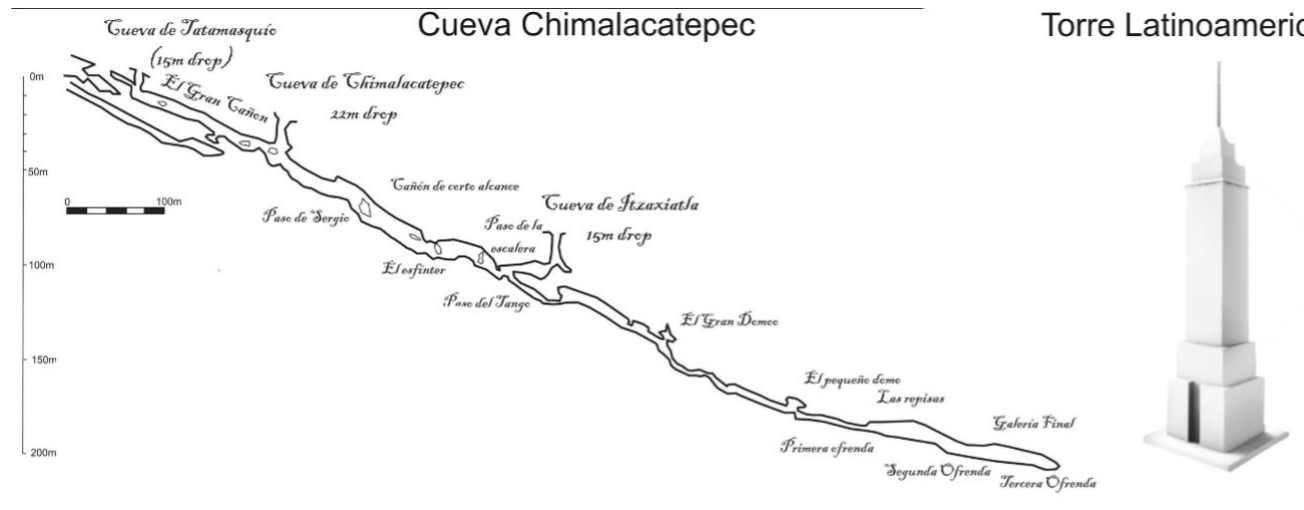

Para acceder a ella, es necesario usar técnicas de espeleología, pues inicia con una entrada de $15 \mathrm{~m}$ de profundidad. Una vez dentro, comenzamos a andar 
Figura 3. Fotografías del tubo de lava Chimalacatepec.

A. Entrada a la cueva de

Chimalacatepec mediante el uso de técnicas verticales. By C. Aspecto del tubo principal. D. Piroestalactitas o estalactitas de lava formadas por el goteo de la roca fundida dentro de la cueva.

Foto de Rafael López Martínez sumidos en la más profunda oscuridad —sólo alumbrados por las lámparas en nuestros cascos-, por un paisaje volcánico lleno de bloques tambaleantes y formaciones caprichosas producidas por la lava. Estas formaciones recuerdan a las estalactitas que tantas veces hemos visto en las cuevas, pero en este caso son de roca volcánica (basalto), formadas por el goteo de la roca derretida cuando la lava aún corría por el interior de estos túneles (ver figura 3). Una manera de imaginarnos cómo se originan, es ver detenidamente una vela encendida derritiéndose y goteando. Esta comparación pareciera muy básica, no obstante, es el método que ha permitido modelar la formación de estas estructuras tan interesantes, conocidas como estalactitas de lava o piro-estalactitas (Vela-Turcott, 2014).

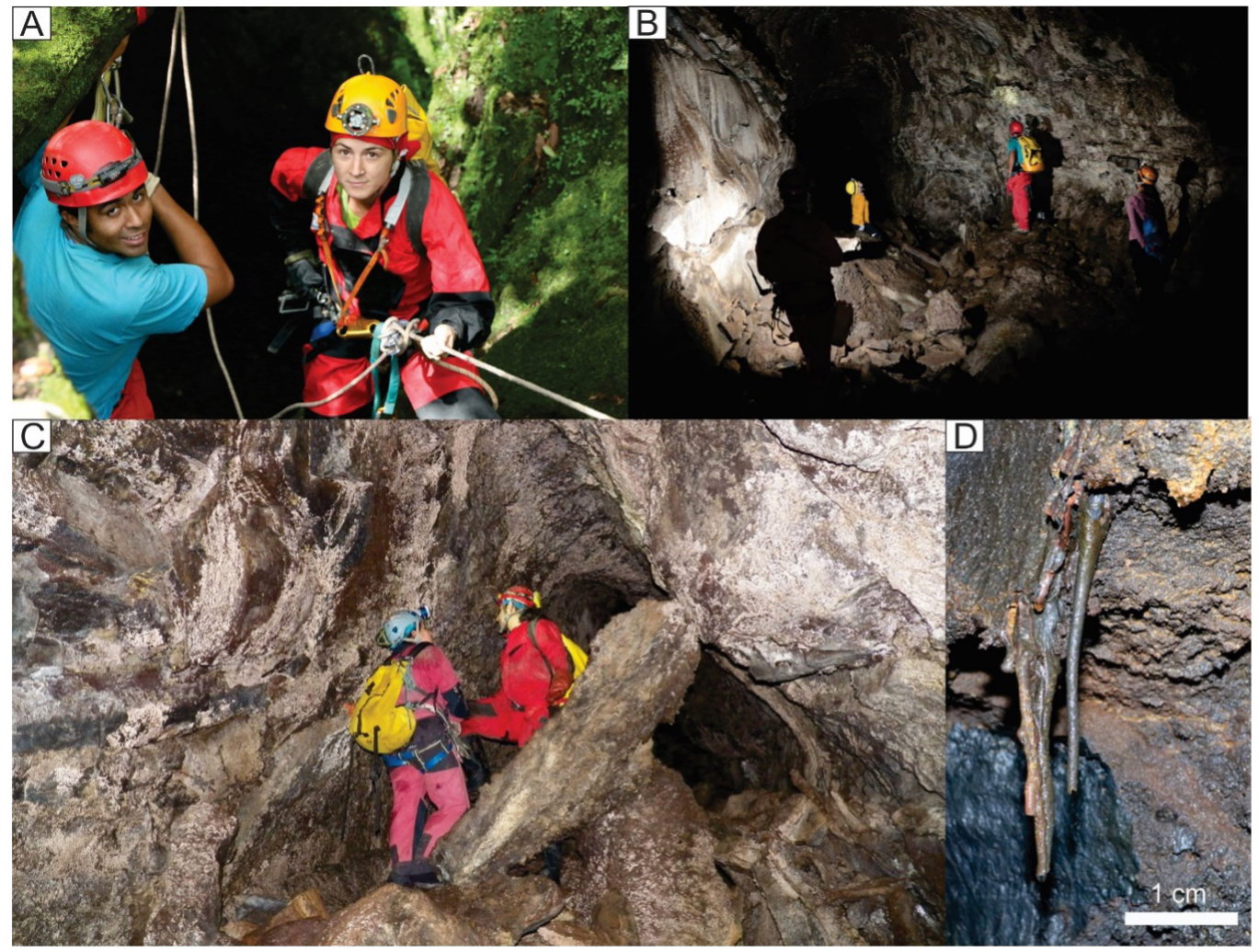

Sin embargo, hay algo que nos llama más la atención en la cueva de Chimalacatepec: la aparición de unas estructuras de colores claros, que evidentemente no estaban hechas por lava.

Los depósitos químicos de las cuevas son llamados espeleotemas. Por ejemplo, las estalactitas y las estalagmitas son tipos de espeleotemas, pero hay una enorme variedad de estos depósitos que no siempre son tan evidentes. Esas formas aplanadas que empezamos a ver dentro de la cueva tienen una composición silícea, en una variedad conocida como ópalo-A ( $\mathrm{SiO} 2+\mathrm{nH} 2 \mathrm{O}$ ), que no tiene cristales, como el cuarzo que todos conocemos, sino que es amorfa, como si se tratara de un gel endurecido (ver figura 4). 
Figura 4. Formas de algunos espeleotemas encontrados en Chimalacatepec. En la izquierda se muestra un espeleotema en forma de "galleta" y a la derecha un conjunto de espeleotemas aplanados y botroidales. Foto de Rafael López Martínez
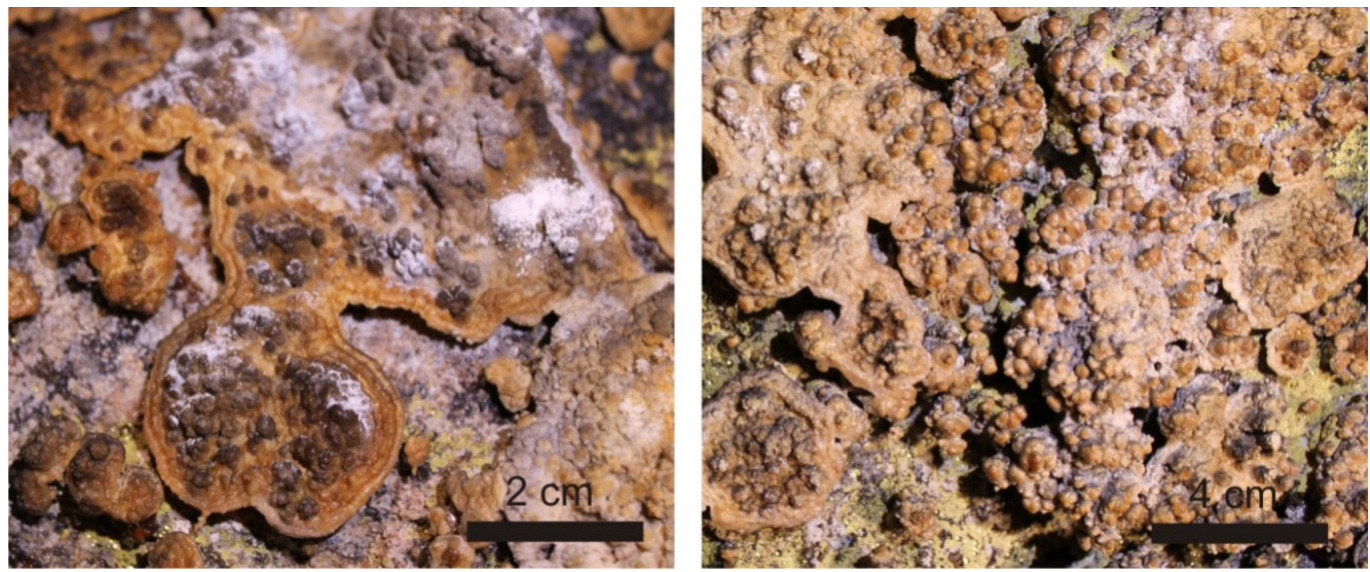

Pero algo parece estar mal. Todos conocemos las estalactitas y estalagmitas: las hemos visto en cuevas y documentales de todo el mundo y siempre hemos escuchado que están compuestas por carbonato de calcio $\left(\mathrm{CaCO}_{3}\right)$. ¿Por qué, entonces, en los tubos de lava serían de sílice?

La respuesta a esa pregunta está en la disponibilidad de un elemento u otro. Por ejemplo, Chimalacatepec está formada en basaltos, roca compuesta por vidrio volcánico, aluminosilicatos y otros minerales. Todos ellos tienen en común una gran cantidad de silicio en su composición química, pero muy poco calcio. Cuando la roca se expone a agentes como la lluvia, la vegetación, el suelo y los microorganismos, estos minerales son transformados y la sílice se libera, por lo que viaja hacia el interior de la cueva a través de las grietas. Por tanto, la aparición de espeleotemas silíceos es poco común, pero posible en ambientes volcánicos como los tubos de lava que estudiamos, o en las rocas graníticas o las areniscas cuarcíferas conocidas en los Tepuis de Venezuela.

En ese momento, dentro de la cueva, hay más preguntas que respuestas. Así que esnecesario hacer lo que todo científico hace: tomar muestras del agua y de los espeleotemas, tratando de no dañar la cueva; medir parámetros de la atmósfera de la cueva, como la temperatura, humedad, $\mathrm{CO}_{2^{\prime}}$ e ir al laboratorio a analizar los datos.

En el laboratorio, ya sin casco, cambiamos la vestimenta de las cuevas por la bata blanca y comienza otra parte fascinante del trabajo del geólogo en su labor milenaria de hacer hablar a las rocas. Pero ellas guardan celosamente sus secretos y sólo los revelarán si hacemos las preguntas correctas.

Los espeleotemas cortados en secciones muy finas son vistos a través de diferentes microscopios. La primera revelación es que están compuestos por microcapas de ópalo-A, que se van acomodando una tras otra, pero de una forma muy particular que recuerda a las primeras estructuras en las que se originó la vida en la Tierra: Ios estromatolitos (ver figura 5A). 
Sin embargo, los estromatolitos —formas de vida que datan de hace 3500 millones de años - existen actualmente en muy pocos lugares del planeta, como en los lagos de Alchichica, Cuatro Ciénagas o Bacalar, en México, y en Bahamas y Australia, por nombrar algunos. Habitan dentro del agua y están expuestos a la luz del sol, características muy diferentes al ambiente oscuro de la cueva volcánica de Chimalacatepec. ¿Será posible que estos espeleotemas estén formados por microorganismos al igual que los estromatolitos?

El microscopio óptico que usamos no puede darnos esta respuesta. Para ello, debemos ir más a detalle, buscar estructuras más pequeñas - - de una milésima parte de un milímetro- dentro de la roca, con el Microscopio Electrónico de Barrido. A los varios minutos de inspección con este microscopio, comienzan a aparecer evidencias de que podríamos estar en lo cierto. Apreciamos atónitos moldes de bacterias fosilizadas dentro de las capas de ópalo-A (ver figuras 5B y 5C). Lo que observamos apunta a que estos espeleotemas están formados por comunidades de bacterias que como tapetes cubren algunas partes de las paredes de esta cueva (ver figura 5D).
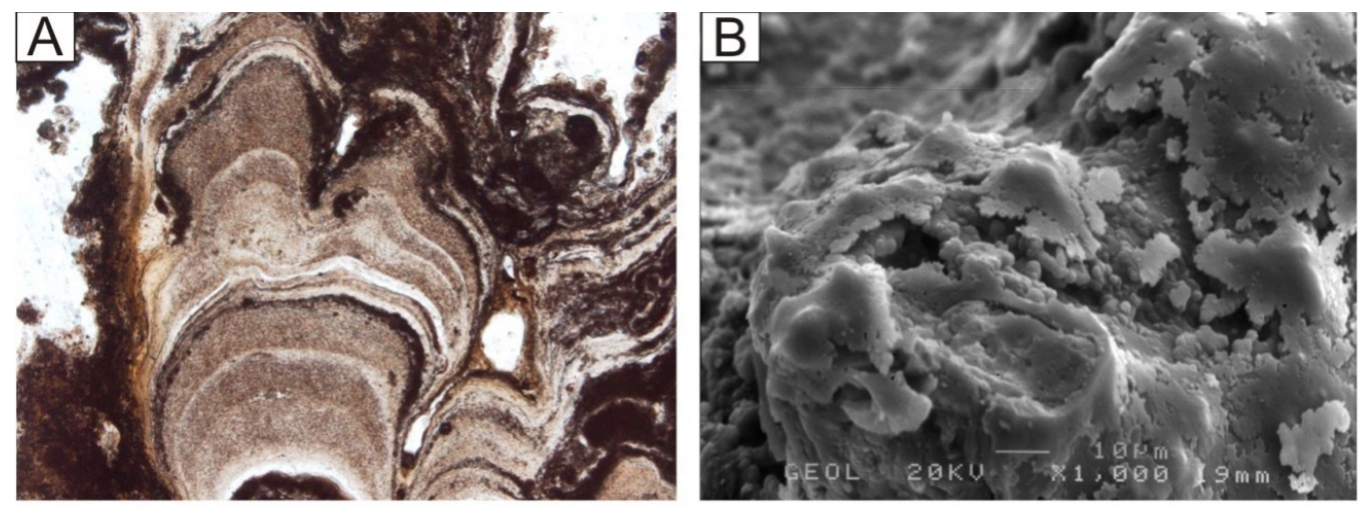

Figura 5. A. Vista al microscopio petrográfico de la laminación interna de los espeleotemas. B y C. Vista al Microscopio Electrónico de Barrido, donde se muestra el ópalo A y los tapetes microbianos fosilizados. D.

Colonias microbianas actuales que cubren algunas secciones de las paredes de la cueva. Foto de Rafael López Martínez
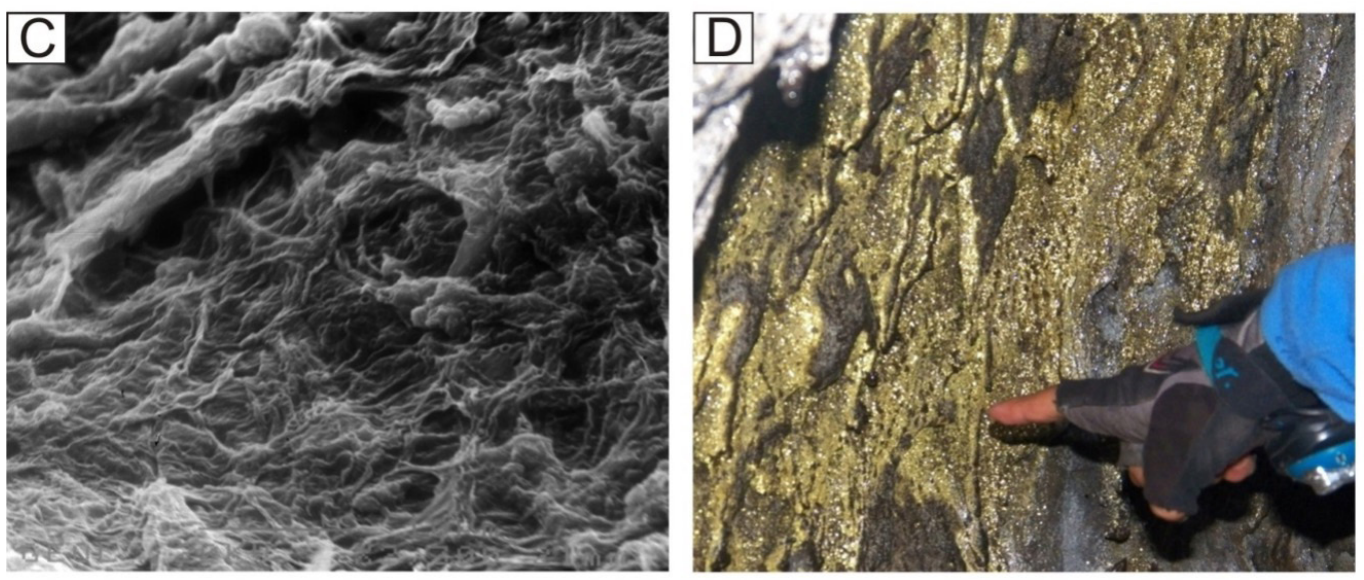

En ese momento, al ver las evidencias de microorganismos fosilizados en el interior de los espeleotemas, pude escuchar en mi mente a Axel platicando con el profesor Lidenbrock en las profundidades del centro de la Tierra: 
-Pero si en estas regionessubterráneas han vivido animales antediluvianos, ¿quién nos dice que algunos de estos monstruos no anden todavía errantes por estas selvas umbrosas o detrás de esas rocas escarpadas?

Y así, una vez más, siguiendo los pasos del profesor Lidenbrock, su pupilo Axel y su guía Hans, el grupo de científicos emprende la búsqueda de vida dentro de estas rocas en las cuevas volcánicas de México. De nuevo, nos encontramos poniendo cuerdas y equipo para descender a la cueva de la que hacía poco habíamos regresado. Pero ahora, nuestro objetivo es saber qué tipo de microorganismos vivían en estos espeleotemas y si eran capaces de crear estas formaciones tan particulares. Para ello, se usa el método de secuenciación de ADN, técnica que nos permite saber si efectivamente los espeleotemas contienen microorganismos como bacterias y que, de alguna manera, pueden vivir en esas condiciones de oscuridad absoluta. Y si esos organismos tan pequeños, lentamente, capa a capa, han ido atrapando las aguas cargadas de gel de sílice y formando estas formaciones estromatolíticas tan particulares.

La tarea no es fácil: muestrear en estos ambientes es complicado, extraer ADN en el laboratorio de ellos aún más. Pero los resultados son claros: existen microorganismos en los espeleotemas que son capaces de vivir en la oscuridad y atrapar la sílice en sus estructuras microbianas.

Estos microorganismos se alimentan de los escasos nutrientes y compuestos inorgánicos que vienen en el agua de goteo y de algunos minerales disueltos generados por el intemperismo de los basaltos. Además, por si esto fuera poco, el ADN reveló que algunos de los microorganismos de Chimalacatepec son parientes de aquellos encontrados en los basaltos de Islandia, muy cerca de nuestro querido Sneffels.

\section{Conclusiones}

A pesar de los descubrimientos aquí narrados, aún falta mucho por entender sobre los microorganismos que viven dentro de estas cuevas y los tipos de espeleotemas que pueden formar. Estos tipos de estudios abren nuevas posibilidades para comprender más sobre el origen mismo de la vida o la posibilidad de comparar en un futuro formas de vida en otros planetas — como Marte-, donde las condiciones son extremas.

¿Acaso los tubos de lava podrían servir como refugio para la vida microbiana en otros planetas? ¿Estos tubos de lava serían similares a los encontrados en Marte o la Luna? Pero esto ya es harina de otro costal. De la Tierra a la Luna es otro magnífico libro de Julio Verne, pero lo dejaremos para futuras aventuras... 


\section{Referencias}

* Detay, M. y Hróarsson, B. (2011). Túneles de lava. Investigación y ciencia, (420), 6267. https://www.investigacionyciencia.es/revistas/investigacion-y-ciencia/la-fsicade-la-inteligencia-533/tneles-de-lava-9131

* Vela-Turcott, G. (2014). Tubos de lava: Un desafío subterráneo en Veracruz. México desconocido. https://www.mexicodesconocido.com.mx/tubos-lava-desafio-

subterraneo-veracruz.html

\section{Agradecimientos}

Este artículo es un resultado directo del proyecto PAPIIT IN113020. Los autores agradecen la participación de los estudiantes de la asignatura Karstología del Posgrado en Ciencias de la Tierra, así como el apoyo brindado en las campañas de campo por Hugo Salgado Garrido, Salvador Trejo Pelayo, Ángeles Verdes, Ramsés Miranda y Nayeli Vargas. Agradecemos especialmente a las autoridades del municipio San Juan Tlacotenco que tan amablemente nos han acogido en la localidad.

\section{Cómo CITAR ESTE ARTículo}

* López Martínez, Rafael Antonio, Daza, Raquel y Alcántara Hernández, Rocio. (2021, marzo-abril). Cuevas volcánicas: entre la realidad y la ficción. Revista Digital Universitaria(RDU),22(2).Dol:http://doi.org/10.22201/cuaieed.16076079e.2021.22.2.3 